\title{
E3B1/ABI-1 isoforms are down-regulated in cancers of human gastrointestinal tract
}

\author{
Rafia A. Baba ${ }^{\mathrm{a}}$, Hina F. Bhat ${ }^{\mathrm{a}}$, Lateef A. Wani ${ }^{\mathrm{b}}$, Muneesa Bashir ${ }^{\mathrm{a}}$, Mudasir M. Wanic, \\ Sumyra K. Qadrid and Firdous A. Khanday,* \\ ${ }^{a}$ Department of Biotechnology, University of Kashmir, Srinagar, Jammu and Kashmir, India \\ ${ }^{\mathrm{b}}$ Department of Pathology, Shri Maharaja Hari Singh Hospital, Srinagar, Jammu and Kashmir, India \\ ${ }^{\mathrm{c}}$ Department of Surgery, Shri Maharaja Hari Singh Hospital, Srinagar, Jammu and Kashmir, India \\ ${ }^{\mathrm{d}}$ Department of Pathology, Sher-i-Kashmir Institute of Medical Sciences, Soura, Srinagar, Jammu and Kashmir, \\ India
}

\begin{abstract}
The expression of E3B1/ABI-1 protein and its role in cancer progression and prognosis are largely unknown in the majority of solid tumors. In this study, we examined the expression pattern of E3B1/ABI-1 protein in histologically confirmed cases of esophageal (squamous cell carcinoma and adenocarcinoma), gastro-esophageal junction, colorectal cancers and corresponding normal tissues freshly resected from a cohort of 135 patients, by Western Blotting and Immunofluorescence Staining. The protein is present in its phosphorylated form in cells and tissues. Depending on the extent of phosphorylation it is either present in hyper-phosphorylated (M. Wt. $72 \mathrm{kDa}$ ) form or in hypo-phosphorylated form (M. Wt. $68 \mathrm{kDa}$ and $65 \mathrm{kDa}$ ). A thorough analysis revealed that expression of E3B1/ABI-1 protein is significantly decreased in esophageal, gastro-esophageal junction and colorectal carcinomas irrespective of age, gender, dietary and smoking habits of the patients. The decrease in expression of E3B1/ABI-1 was consistently observed for all the three isoforms. However, the decrease in the expression of isoforms varied with different forms of cancers. Down-regulation of E3B1/ABI-1 expression in human carcinomas may play a critical role in tumor progression and in determining disease prognosis.
\end{abstract}

Keywords: Eps8 binding protein, abelson interactor protein, signal transduction, esophageal squamous cell carcinoma, adenocarcinoma, colorectal cancers

\section{Introduction}

E3B1 (Eps8-SH3 domain binding protein1), which is a human homolog to the mouse Abelson interactor1 gene (Abi-1) [1], was isolated as an Eps8 binding protein [2]. E3B1/ABI-1 is an adaptor protein that has been found to mediate a number of signal pathways related to cancer cell proliferation, apoptosis, adhesion, and migration in breast cancer, BCR-Abl-induced leukemia, colon cancer, and melanoma, both in vitro and in vivo [3-8]. E3B1/ABI-1 was found to be part of several macromolecular complexes, including a trimer-

${ }^{*}$ Corresponding author: Firdous A. Khanday, Department of Biotechnology, University of Kashmir, 190006, Jammu and Kashmir, India. Tel.: +91 990646 2206; Fax: +91 194242 8723; E-mail: khandayf@kashmiruniversity.net. ic signaling complex, where it closely interacts with Eps8 and Sos-1, activating Rac1 [9]. In turn, Rac1 has been shown to be involved in production of Reactive Oxygen Species [10,11] and WAVE2 signaling complex. Activated WAVE proteins lead to enhanced actin nucleation via the Arp2/3 complex [12-14]. As an adaptor protein, E3B1/ABI-1 is involved in actin reorganization and lamellipodia formation which are believed to play critical roles in cell migration during metastasis [15]. E3B1/ABI-1 has been proposed as a potential tumor suppressor [16]. Recent findings have indicated that the gene encoding E3B1 is deleted in prostate cancer, and also loss of its expression accompanies the development and progression of some types of leukemia's $[17,18]$. Its role in cell mobility and decreased expression in some forms of cancers may be an indicative that E3B1/ABI-1 is involved in one or more of the steps leading to tumor progression or 


\begin{tabular}{|c|c|c|c|c|c|}
\hline Cancer type & \multicolumn{2}{|c|}{ Males } & \multicolumn{2}{|l|}{ Females } & $\begin{array}{l}\text { NO. of samples } \\
\text { showing \%age } \\
\text { decrease of E3B1 } \\
\text { EXPRESSION }\end{array}$ \\
\hline$($ Total $n=135)$ & $\mathrm{n}$ & $\%$ & $\bar{n}$ & $\%$ & \\
\hline Gender & 81 & 60.00 & 54 & 40.00 & - \\
\hline Average years* & $59 \pm 14.84$ & - & $51.89 \pm 14.23$ & - & - \\
\hline \multicolumn{6}{|l|}{ Smoking status } \\
\hline Non-smokers & 57 & 70.37 & 48 & 88.88 & - \\
\hline Ex-smokers & 24 & 29.62 & 6 & 11.11 & - \\
\hline Esophageal squamous Cell & 15 & 18.51 & 12 & 22.22 & $70 \%$ \\
\hline Poorly differentiated & 6 & 7.40 & 3 & 5.55 & $75 \%$ \\
\hline Well differentiated & 9 & 11.11 & 9 & 16.66 & $65 \%$ \\
\hline Esophageal adenocarcinoma & 7 & 8.64 & 6 & 11.11 & $72 \%$ \\
\hline Gastro-esophageal junction & 20 & 24.69 & 12 & 22.22 & $90 \%$ \\
\hline Colon & 18 & 22.22 & 10 & 18.51 & $88 \%$ \\
\hline Rectal & 21 & 25.92 & 14 & 25.92 & $94 \%$ \\
\hline
\end{tabular}

*Values are expressed as Mean $\pm \mathrm{SD}$.

metastasis. To understand this role a careful analysis of E3B1/ABI-1 protein expression needs to be carried out in different forms of human cancers. Here, in this study we have carried a systematic protein expression analysis on human esophageal (squamous and adenocarcinoma), gastroesophageal junction and colorectal cancers.

\section{Materials and methods}

\subsection{Patients}

A total of 135 tissue specimens were obtained with consent from patients who underwent curative surgical resection from April 2008 to November 2010 at the Department of General Surgery, Shri Maharaja Hari Singh Hospital, Srinagar, (India). Archival materials were reviewed by experienced pathologists (Department of Pathology, Shri Maharaja Hari Singh Hospital and Department of Pathology, Sher-i-Kashmir Institute of Medical Sciences), to select a representative tumor block and surrounding normal mucosal tissue block for each case. The patient group included 81 men and 54 women (Table 1). Clinical diagnosis was confirmed in all cases by histo-pathological examination. The study protocol was approved by the Shri Maharaja Hari Singh Hospital, Research Ethics Committee. The patients were not given any radiotherapy or chemotherapy before surgery. The adjacent normals taken for the study were obtained by macro-dissection, about $3 \mathrm{~cm}$ away from the tumorigenic area. Tissues were immediately snap frozen by immersion in liquid nitrogen N2 (1) and stored at -80 degree until use.

\subsection{Chemicals}

Bradford microprotein estimation kit was purchased from Genei Laboratories (Bangalore, India). PVDF membrane was purchased from Whatman $\mathrm{GmbH}$, (Dassel Germany). Electrophoresis reagents were obtained from Sigma-Aldrich (St Louis, MO, USA), Qualigens (Mumbai, India) and Spectrochem (Mumbai, India). All the chemicals for carrying out protein extraction and Western blotting were of analytical grade and were acquired from Sigma-Aldrich.

\subsection{Protein extraction and estimation}

Tissue was disintegrated using $0.5 \%$ trypsin-EDTA at $37^{\circ} \mathrm{C}$ for $5 \mathrm{~min}$, centrifuged at $12000 \mathrm{rpm}$ for $5 \mathrm{~min}$, rinsed twice with ice-cold PBS, pH 7.4. Whole cell lysates were incubated on ice with NP-40 lysis buffer containing protease and phosphatase inhibitors $(20 \mathrm{mM}$ Tris-HCl, pH 8.0, 137 mM NaCl, 1\% Nonidet P-40, 1\% glycerol, 2 mM EDTA, $10 \mathrm{mM} \mathrm{NaF,} 1 \mathrm{mM}$ PMSF, protease inhibitor cocktail $10 \mu \mathrm{l}$ per $1 \mathrm{ml}$ of lysis buffer) for 45 minutes and then clarified by centrifugation at $12,000 \mathrm{rpm}$ for 10 minutes at $4{ }^{\circ} \mathrm{C}$ to btain the extract. Protein concentration was determined spectrophotometrically (Shimadzu, Kyoto, Japan) at $595 \mathrm{~nm}$ with the Bradford assay kit.

\subsection{Antibodies}

Rabbit polyclonal antibodies against E3B1 and Vinculin, and Alkaline phosphatase conjugated anti-rabbit IgG secondary antibody was purchased from Santa Cruz Biotechnology Inc., Santa Cruz, CA, USA. AntiRabbit IgG Alexa Fluor-488 antibody was gift from Dr. Ellora Sen (NCBR, New Delhi). 

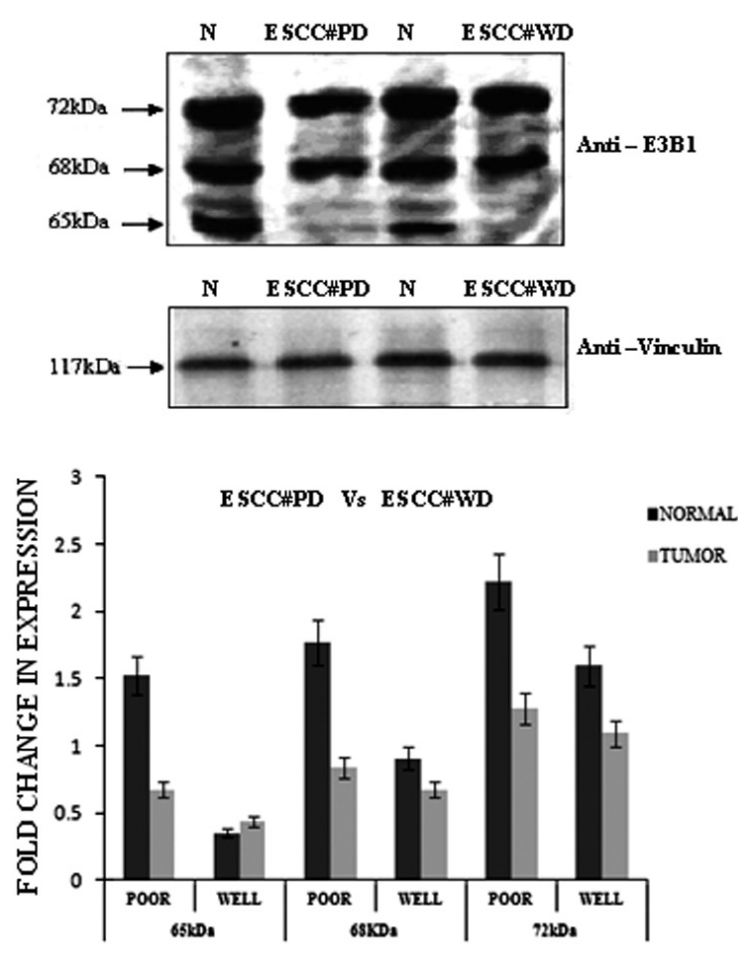

Fig. 1. Immunoblot showing the decreased expression of E3B1 protein and Bar chart comparing the fold change in expression levels in well differentiated (ESCC\#WD) and poorly differentiated (ES$\mathrm{CC \# PD)}$ esophageal squamous cell carcinoma as compared to their adjacent normals $(\mathrm{N})$.

\subsection{Western blot analysis}

$10 \%$ SDS-PAGE was used to resolve 25 micrograms of protein extract preheated at $100^{\circ} \mathrm{C}$ for $3 \mathrm{~min}$ in reducing sample buffer containing $50 \mathrm{mM}$ Tris- $\mathrm{HCl}(\mathrm{pH}$ $6.8), 2 \%$ SDS, $10 \%$ glycerol, $0.1 \%$ bromophenol blue, $100 \mathrm{mM} \beta$-mercaptoethanol and the resolved proteins were transferred onto PVDF membrane (Whatmann) blocked with TBS supplemented with $0.1 \%$ Tween 20 and $5 \%(\mathrm{w} / \mathrm{v})$ fat-free powder milk for $1.5 \mathrm{hrs}$. The membranes were then rocked overnight with primary antibody (1:500 dilution of anti-E3B1 Ab in 5\% skimmed milk in TBS, 1:1000 dilution of anti-Vinculin $\mathrm{Ab}$ in $5 \%$ skimmed milk in TBS) at $4{ }^{\circ} \mathrm{C}$. Thereafter, the membranes were washed in TBS supplemented with $0.1 \%$ Tween 20 followed by incubation with antirabbit IgG (1:3000 dilution in 5\% skimmed milk in TBS) conjugated to alkaline phosphatase for $2 \mathrm{hrs}$. The blots were then washed again and antibody binding signals were detected by treating the membrane with $\mathrm{BCIP} / \mathrm{NBT}$ solution, incubated and protected from light for 10-15 min until the desired color intensity was ob-
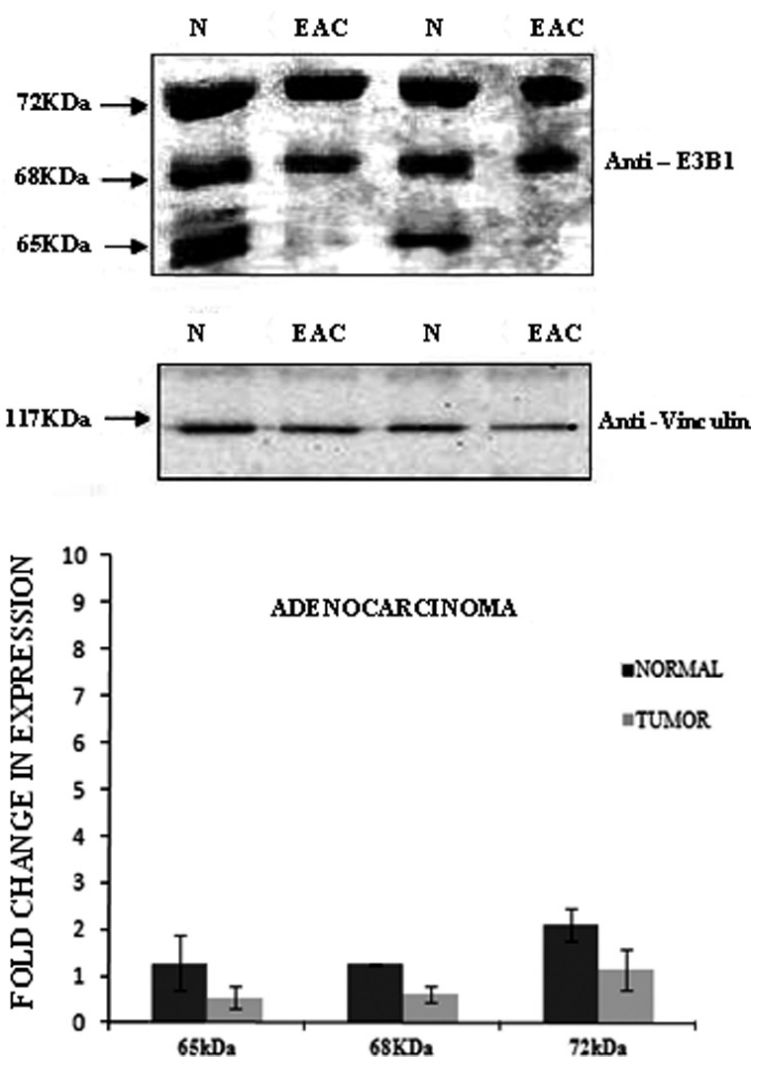

Fig. 2. Immunoblot showing the decreased expression of E3B1 protein and Bar chart comparing the fold change in expression levels in the esophageal adenocarcinoma (EAC) as compared to their adjacent normals $(\mathrm{N})$.

tained. All results were confirmed in at least three independent experiments.

\subsection{Immunohistochemistry}

Formalin fixed, paraffin-embedded tissues were cut into $5 \mu \mathrm{m}$ serial sections on a conventional microtome, overlaid onto glass slides and processed for immunohistochemistry. The sections were de-waxed, washed thoroughly in phosphate-buffered saline (PBS) and microwaved in $0.1 \mathrm{M}$ citrate buffer $(\mathrm{pH}$ 6.0) for $5 \mathrm{~min}$ (x2), again washed with PBS, and post-fixed with $4 \%$ paraformaldehyde and finally washed thrice with PBS. The sections were then blocked with $1 \%$ non-fat dried milk in buffer for $2 \mathrm{~h}$ at room temperature, and then incubated with primary anti-E3B1 antibody (1:100) diluted in blocking buffer overnight at $4{ }^{\circ} \mathrm{C}$. After thoroughly washing in PBS $(3 \times 5 \mathrm{~min})$, the sections were then incubated with an Anti-Rabbit IgG Alexa Fluor488 antibody was diluted $(1: 200)$ in blocking buffer. After washing the tissue three times with PBS, the sec- 

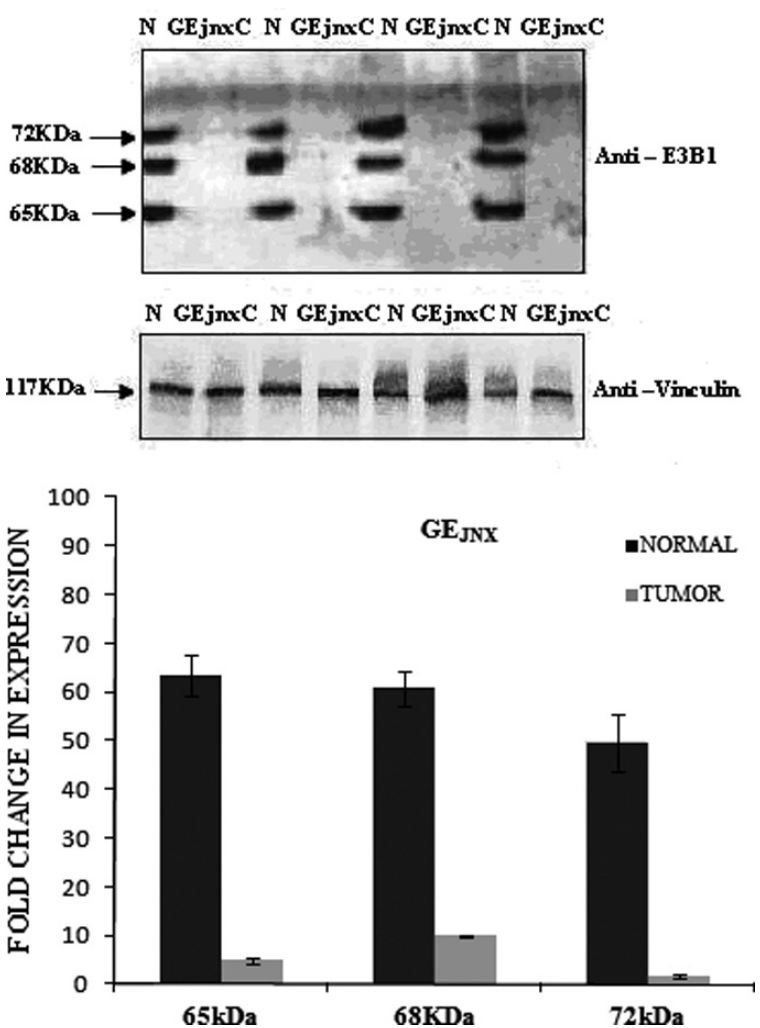

Fig. 3. Immunoblot showing the reduced expression of E3B1 protein and Bar chart comparing the fold change in expression levels in gastro-esophageal junction carcinoma $(\mathrm{GEjnxC})$ as compared to their adjacent normals $(\mathrm{N})$

tions were viewed under fluorescence microscope (Leica). For negative control studies, the primary antibody treatment was omitted (data not shown).

\subsection{Hematoxylin and eosin staining}

Tissue sections were deparaffinised followed by rinsing in xylene, re-hydration in absolute alcohol and final rinse with graded alcohol. Slides were washed briefly in distilled water and stained in hematoxylin solution for 8 minutes and followed by wash in running tap water for 5 minutes. Slides were differentiated in $1 \%$ acid alcohol for 30 seconds and again followed by wash with running tap water for 1 minute Bluing was carried out in $0.2 \%$ ammonia water or saturated lithium carbonate solution for 30 seconds to 1 minute and washing was repeated as in the previous step. Slides were rinsed in $95 \%$ alcohol (10 dips). Now slides were counterstained in eosin-phloxine solution for 30 seconds to 1 minute and dehydrated through $95 \%$ alcohol, 2 changes of absolute alcohol, 5 minutes each. Slides were finally now washed in xylene and mounted for viewing.
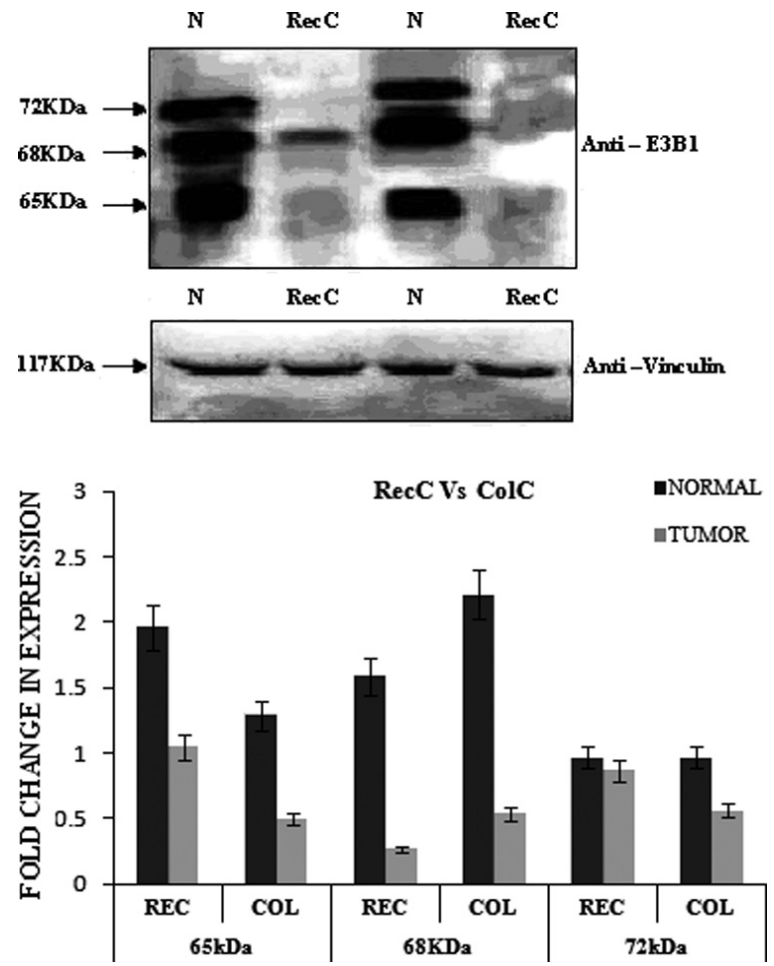

Fig. 4. Immunoblot showing the down-regulated expression of E3B1 in Colon cancer (ColC) and Rectal cancer ( $\mathrm{RecC}$ ) as compared to their adjacent normals $(\mathrm{N})$. *Bar chart comparing the fold change in expression levels of E3B1 protein in Rectal and Colon cancers as compared to their normals.

\subsection{Statistics}

The results were calculated as mean \pm SD. For statistical analysis of the data, t-test (Microsoft Excel) was used, to evaluate association between clinicopathological variables. Statistical significance was considered when $p<0.05$.

\section{Results}

E3B1/ABI-1 a polypeptide of length 480 amino acids is unique in having large number of Ser and Thr residues. This protein is present as a phosphorylated form in cells and tissues. Depending on the extent of phosphorylation it is either present in hyper-phosphorylated (M. Wt. $72 \mathrm{kDa}$ ) form or in hypo-phosphorylated form (M. Wt. $68 \mathrm{kDa}$ and $65 \mathrm{kDa}$. p65 E3B1 is a phosphoserine-containing protein and $\mathrm{p} 68 \mathrm{E} 3 \mathrm{~B} 1$ and $\mathrm{p} 72 \mathrm{E} 3 \mathrm{~B} 1$ are hyperserinephosphorylated forms of p65E3B1 [2]. In this study we have looked at the expression pattern of these iso- 

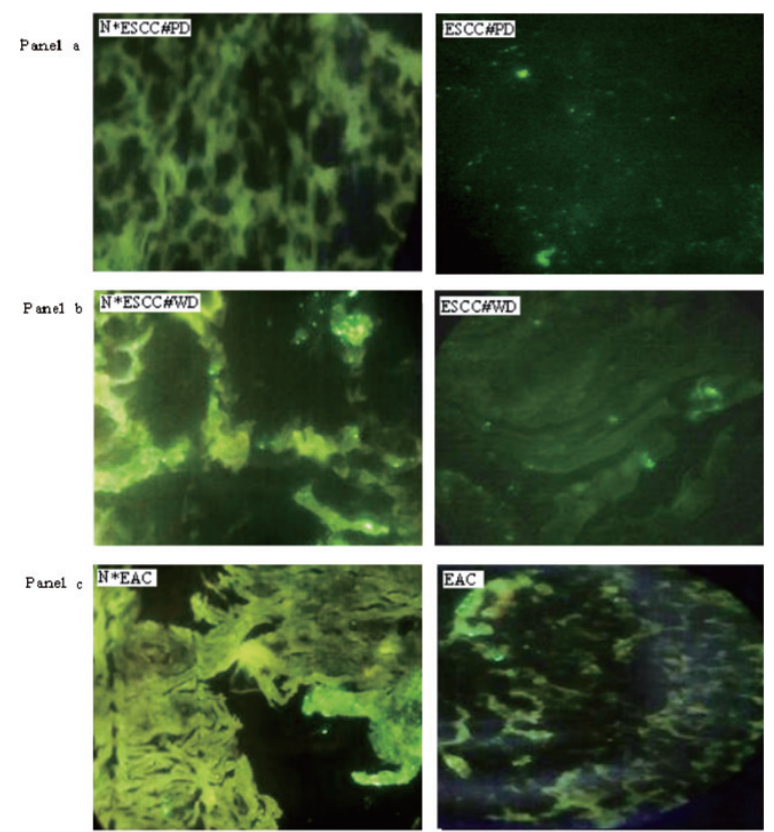

Fig. 5. Immunofluorescence staining of esophageal tissue sections. Expression of E3B1 protein a: Poorly Differentiated (ESCC\#PD), b: Well Differentiated (ESCC\#WD), Esophageal Squamous Cell Carcinoma and c: Esophageal Adenocarcinoma (EAC) respectively, with respect to their adjacent normals $(\mathrm{N})$. (Images were captured at 40X magnification). )

forms in different forms of human cancers. We carried out Western blot analysis of E3B1/ABI-1 protein in esophageal squamous cell carcinoma and adenocarcinoma (ESCC, AC). Results indicated a consistent decrease in the expression of all the three isoforms i.e., $65 \mathrm{kDa}, 68 \mathrm{kDa}$ and $72 \mathrm{kDa}$ in esophageal well and poorly differentiated when compared to their normals (Fig. 1). Normal here represents the tissue from same patient dissected $3 \mathrm{~cm}$ away from the site of tumor [19, 20]. We consistently observed a total absence of $65 \mathrm{kDa}$ isoform and also a decrease of expression of 68 and $72 \mathrm{kDa}$ isoforms in esophageal squamous and adenocarcinomas (Figs 1 and 2). Western blot expression analysis was carried out on gastro-esophageal junction and colorectal cancers from independent patients. The results in gastro-esophageal junction carcinomas indicated a consistent decrease of E3B1/ABI-1 protein expression in these carcinomas when compared to their adjacent normal controls (Fig. 3). In colorectal cancers, we observed decrease in the expression of all the three ispfoms of the E3B1 protein as compared to their nomals (Fig. 4). The decrease in the E3B1/ABI-1 expression was observed to be independent of pathological grading, age, sex, dietary and smoking habits of the patients (Table 1). Vinculin protein was used as loading con-
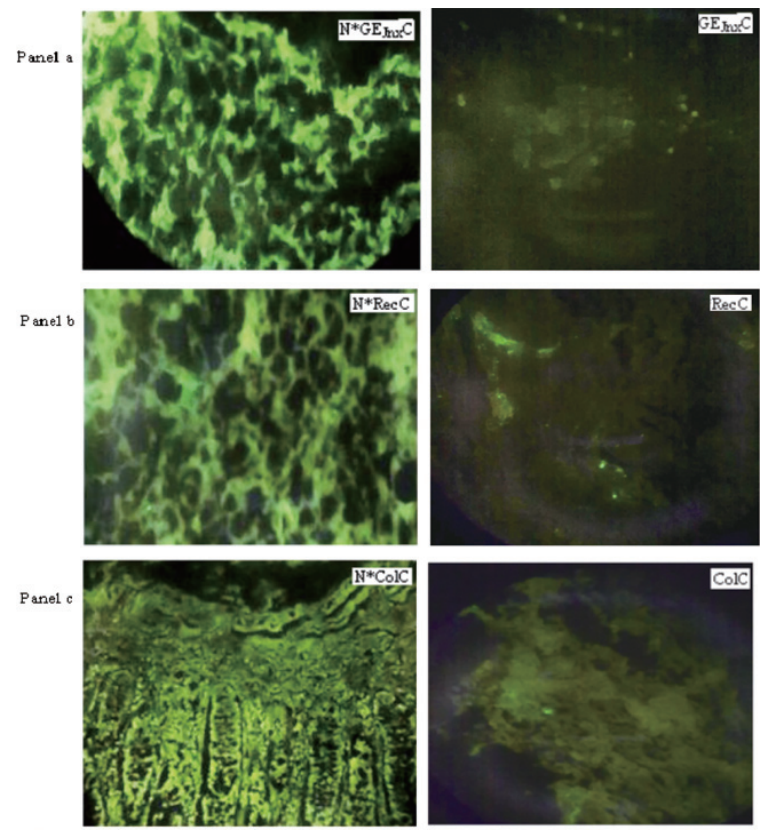

Fig. 6. Immunofluorescence staining of tissue sections. Expression of E3B1 protein a: Gastro-Esophageal Junction Cancer (GEJnxC), b: Rectal Cancer (RecC) and c: Colon Cancer (ColC) respectively, with respect to their adjacent normals $(\mathrm{N})$. (Images were captured at 40X magnification)

trol in all the experiments. Furthermore, Immunofluorescence staining of the tissue sections showed lesser signal of flourescence obtained in cancers as compared to their respective normals which is consistent with the results obtained with Western Blotting (Figs 5 and 6). Immunofluorescence studies indicate a less difference when cancer samples of esophagus were compared with their respective normals (Fig. 5a, b, c) as has been observed in Western Blotting experiments (Figs 1, 2). Hematoxylin and Eosin staining of the normal and different cancerous tissues was performed on all the samples (Figs 7 and 8) to demonstrate the authenticity of the tissue architecture.

\section{Discussion}

The mechanism by which E3B1/ABI-1 protein may exert its tumor suppressor activity in cancer development and progression remains unclear. Previous studies have shown that the process of actin polymerization and depolymerization is fundamental to the cellular control of cell shape, adhesion, and migration. Although the role of E3B1/ABI-1 in actin reorganization has been well described, its role in cell growth and tumorigenesis 

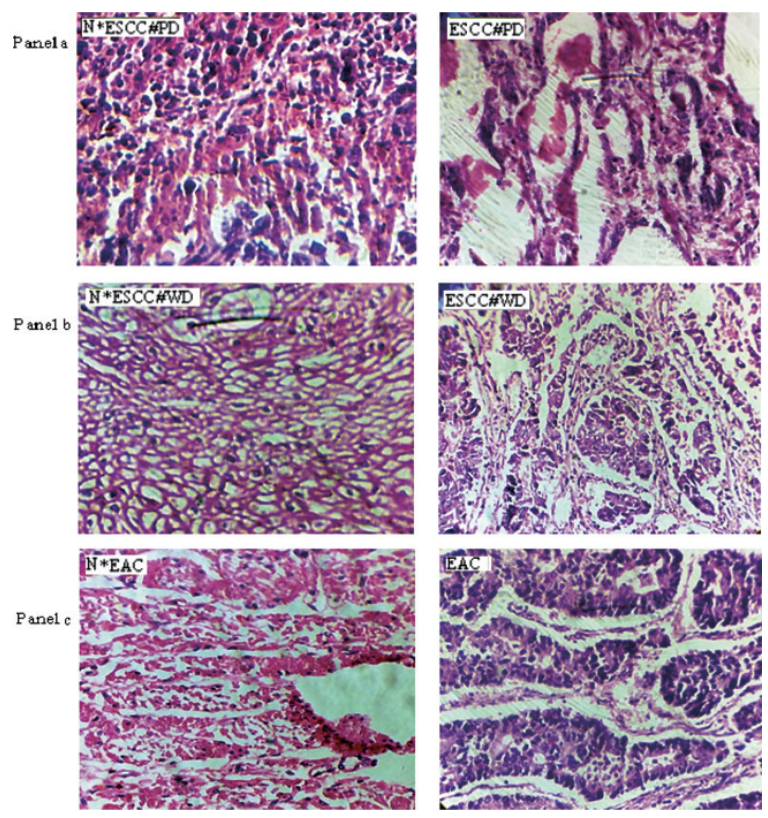

Fig. 7. Hematoxylin and Eosin staining of the normal and cancerous tissues. a: Poorly Differentiated (ESCC\#PD), b: Well Differentiated (ESCC\#WD), Esophageal Squamous Cell Carcinoma and c: Esophageal Adenocarcinoma (EAC) respectively, with respect to their adjacent normals $(\mathrm{N})$. (Images were captured at $40 \mathrm{X}$ magnification).

remains unexplored. Some studies have reported that E3B1/ABI-1 promotes oncogenesis and cancer progression. E3B1/ABI-1 has been found to positively regulate breast cancer cell proliferation, migration, and invasion, as well as annulment of lamellipodia formation, and this role may be mediated via the phosphatidylinositol 3-kinase pathway [5]. E3B1/ABI-1 gene silencing by short hairpin RNA attenuated Bcr-Abl-induced abnormal actin remodeling and membrane-type-1 matrix metalloproteinase clustering, as well as inhibiting cell adhesion and migration on fibronectin-coated surfaces has been reported [21]. Knockdown of E3B1 expression in Bcr-Abl-transformed $\mathrm{Ba} / \mathrm{F} 3$ cells was shown to limit the leukemogenic potential of these cells in NOD/ SCID mice, and revealed that E3B1 contributes to BcrAbl-induced leukemogenesis partly through Src family kinases. Conversely, E3B1 also appears to be a tumor suppressor. Some reports have indicated that overexpression of E3B1 inhibits the growth and transforming activity of $\mathrm{v}$-Abl in NIH3T3 cells, as well as the epidermal-growth-factor- and $\mathrm{v}$-Abl-induced activation of extracellular signal-regulated kinase in 293 T cells [2, 22-25]. This suggests a potential negative regulatory role for E3B1 in the signaling mediated by epidermal growth factor. Other studies have found that loss of

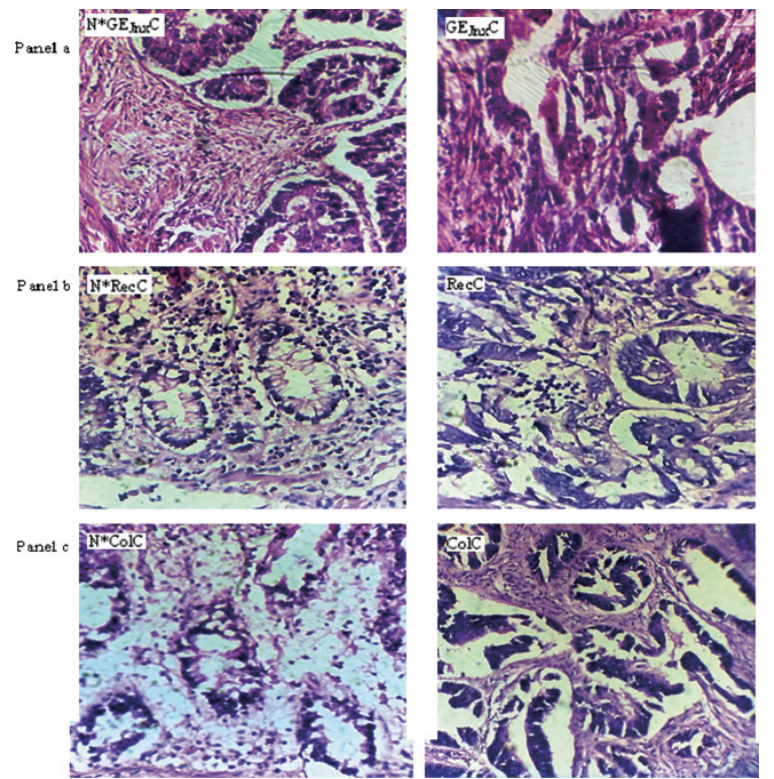

Fig. 8. Hematoxylin and Eosin staining of the normal and cancerous tissues. a: Gastro-Esophageal Junction Cancer (GEJnxC), b: Rectal Cancer (RecCand c:) Colon Cancer (ColC) respectively, with respect to their adjacent normals $(\mathrm{N})$. (Images were captured at $40 \mathrm{X}$ magnification).

E3B1 may play a role in human prostatic adenocarcinoma and the development of human Bcr-Abl-positive leukemia $[16,17]$. This apparently contradictory expression pattern of E3B1 across different tumors suggests that this protein may play multiple diverse roles, potentially by participating in the formation of diverse macromolecular complexes and in multiple signal pathways. It is known that E3B1 forms complex with Eps8 and sos 1 in activating rac1 RhoGTPase [26] it is possible that its loss or downregulation might help cells to evade apoptosis and hence leading to proliferation.

Nevertheless, our results are consistent with the proposed role of E3B1/ABI-1 in other malignancies, and provide the first evidence that nearly lost or down-regulated or differentially expressed forms of E3B1/ABI-1 may play a similarly important role in advanced esophageal, gastro-esophageal and colorectal cancers. However, because the prognosis of cancer patients is affected by a complex array of factors, the specific utility of differences in phohorylation status of E3B1/ABI-1 and its expression in evaluating prognostic and/or predictive value must await further invivo and stratified clinical studies that include a larger number of samples. Further studies are necessary to more precisely define the molecular mechanisms of E3B1/ABI-1 signaling pathways in the development and progression of these cancers. 


\section{Acknowledgements}

This work was supported in part by The Department of Science \& Technology, New Delhi, No. SR/FT/L35/2006. The Department of Biotechnology, Ministry of Science and Technology, Government of India, under the scheme "Innovative Young Biotechnologist Award", No. BT/B1/12/040/2005. We are grateful to Dr. Ellora Sen (Scientist at NCBR, New Delhi) for providing Alexa Fluor-488 antibody as a gift. We are grateful to Mr. Taseem A. Mokhdomi for helping us with densitiometric analysis.

\section{Conflict of interest}

The authors declare that no conflict of interest exists.

\section{References}

[1] Morerio C, Rosanda C, Rapella A, Micalizzi C, Panarello C. Is $\mathrm{t}(10 ; 11)(\mathrm{p} 11.2 ; \mathrm{q} 23)$ involving MLL and ABI-1 genes associated with congenital acute monocytic leukemia? Cancer Genet. Cytogenet 2002; 139: 57-9.

[2] Biesova Z, Piccoli C, Wong WT. Isolation and characterization of e3B1, an eps 8 binding protein that regulates cell growth. Oncogene 1997; 14: 233-41.

[3] Dai Z, Kerzic P, Schroeder WG, McNiece IK. Deletion of the Src homology 3 domain and C-terminal proline-rich sequences in Bcr-Abl prevents $\mathrm{Abl}$ interactor 2 degradation and spontaneous cell migration and impairs leukemogenesis. J .Biol Chem. 2001; 276: 28954-60.

[4] Funato Y, et al. IRSp53/Eps8 complex is important for positive regulation of Rac and cancer cell motility/invasiveness. Cancer Res. 2004; 64: 5237-44.

[5] Wang C, et al. Abelson interactor protein-1 positively regulates breast cancer cell proliferation, migration, and invasion. Mol Cancer Res 2007; 5: 1031-9.

[6] Leng Y, et al. Abelson-interactor-1 promotes WAVE2 membrane translocation and Abelson-mediated tyrosine phosphorylation required for WAVE2 activation. Proc Natl Acad Sci USA 2005; 102: 1098-103.

[7] Stuart JR, Gonzalez FH, Kawai H, Yuan ZM. c-Abl interacts with the WAVE2 signaling complex to induce membrane ruffling and cell spreading. J Biol Chem 2006; 281: 31290-7.

[8] Gu Y, Souza RF, Wu RF, Xu YC, Terada LS. Induction of colonic epithelial cell apoptosis by p47-dependent oxidants. FEBS Lett 2003; 540: 195-200.

[9] Scita G, et al. Eps8 and E3b1 transduce signals from Ras to
Rac. Nature 1999; 401(6750): 290-293.

[10] Khanday FA, et al. SOS-mediated activation of Rac1 by p66shc. J Cell Bio 2006a; 172: 817-822.

[11] Khanday FA, et al. Rac1 leads to phosphorylation-dependent increase in stability of the p66shc adaptor protein: Role in rac1-induced oxidative stress. Mol Biol Cell 2006b; 17: 122129.

[12] Ichigotani Y, Fujii K, Hamaguchi M, Matsuda S. In search of a function for the E3B1/Abi2/Argbp1/NESH family. Int J Mol Med 2002; 9: 591-595.

[13] Innocenti M, et al. Phosphoinositide 3-kinase activates Rac by entering in a complex with Eps8, Abi1, and Sos-1. J Cell Biol 2003; 160: 17-23.

[14] Innocenti $\mathrm{M}$, et al. Abi1 is essential for the formation and activation of a WAVE2 signalling complex. Nat Cell Biol 2004; 6: 319-327.

[15] Ridley AJ. Rho GTPases and cell migration. J Cell Sci 2001; 114: 2713-22.

[16] Jenei V, Jakus J. The role of EGF receptor-dependent e3B1/Abi1 protein as a tumor suppressor protein in malignant tumors. Orv Hetil 2005; 146: 1293-9.

[17] Macoska JA, et al. Loss of expression of human spectrin src homology domain binding protein 1 is associated with $10 \mathrm{p}$ loss in human prostatic adenocarcinoma. Neoplasia 2001; 3 : 99-104.

[18] Dai Z, et al. Oncogenic abl and src tyrosine kinases elicit the ubiquitin-dependent degradation of target proteins through a Ras-independent pathway. Genes Dev 1998; 12: 1415-24.

[19] Bashir M, et al. P66shc and its downstream Eps8 and Rac1 proteins are upregulated in esophageal cancers. Cell Communication and Signaling 2010; 8: 13.

[20] Bhat HF, et al. Alpha-1-Syntrophin protein is differentially expressed in human cancers 2010; Biomarkers Feb; 16(1): 31-6.

[21] Yu W, et al. ABI1 gene silencing by short hairpin RNA impairs Bcr-Abl-induced cell adhesion and migration in vitro and leukemogenesis in vivo. Carcinogenesis 2008; 29: 1717-24.

[22] Shi Y, Alin K, Goff SP. Abl-interactor-1, a novel SH3 protein binding to the carboxy-terminal portion of the Abl protein, suppresses w-abl transforming activity. Genes Dev 1995; 9: 2583-97.

[23] Jenei V, Andersson T, Jakus J, Dib K. E3B1, a human homologue of the mouse gene product ABI1, sensitizes activation of Rap1 in response to epidermal growth factor. Exp Cell Res 2005; 310: 463-73.

[24] Ikeguchi A, Yang HY, Gao G, Goff SP. Inhibition of v-abl transformation in 3T3 cells overexpressing different forms of the abelson interactor protein ABI1. Oncogene 2001; 20: 4926-34.

[25] Fan PD, Goff SP: Abl interactor 1 binds to sos and inhibits epidermal growth factor- and v-abl-induced activation of extracellular signal-regulated kinases. Mol Cell Biol 2000; 20: 7591-601.

[26] Khanday FA et al. Sos-mediated activation of rac1 by p66shc. J Cell Biol. 2006; 172(6): 817-22. 


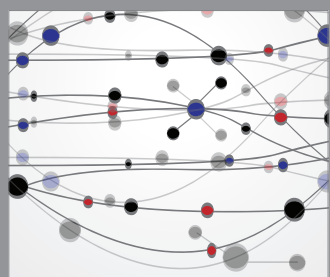

The Scientific World Journal
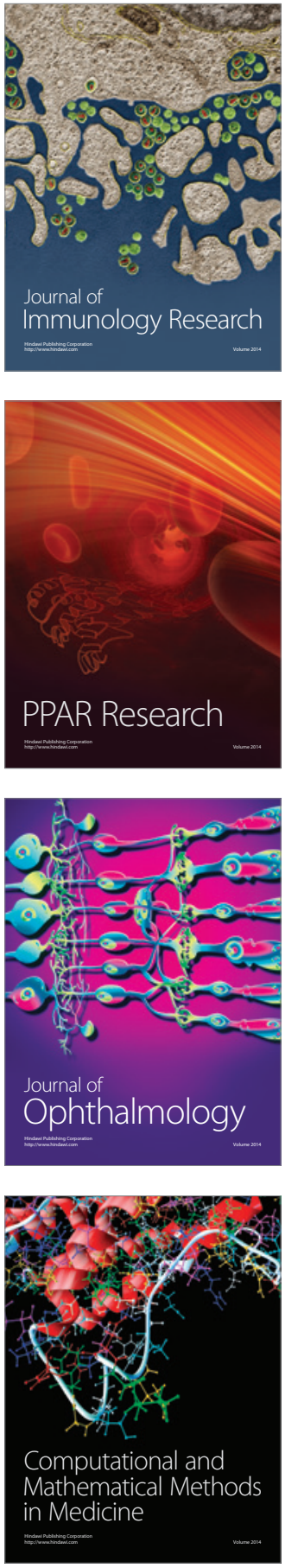

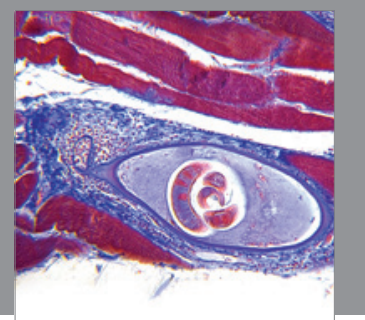

Gastroenterology

Research and Practice
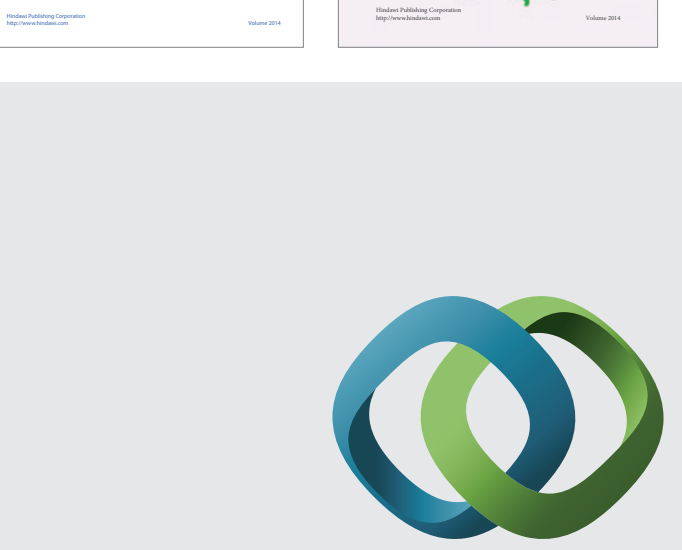

\section{Hindawi}

Submit your manuscripts at

http://www.hindawi.com
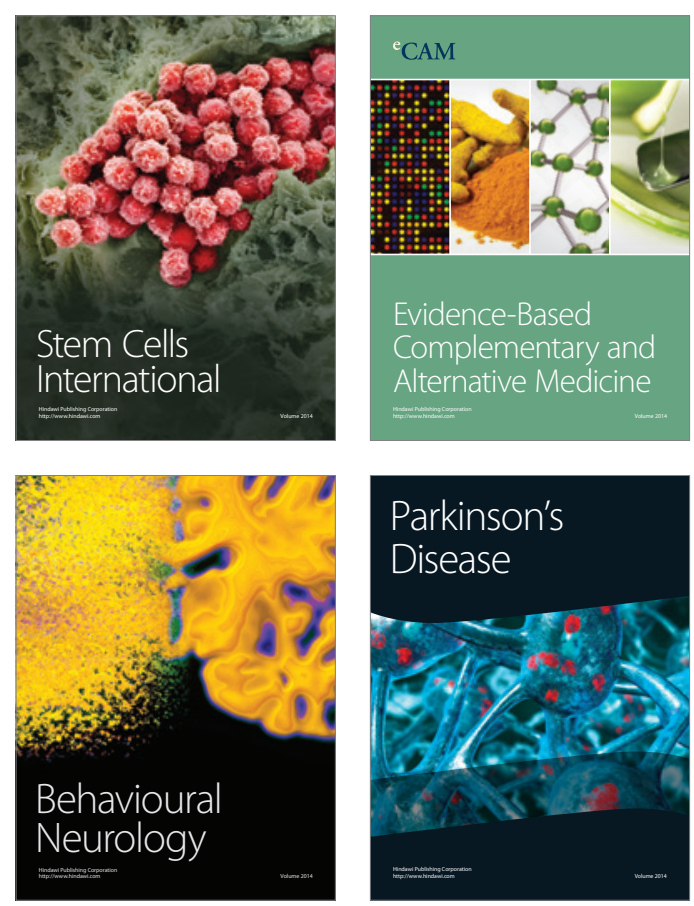

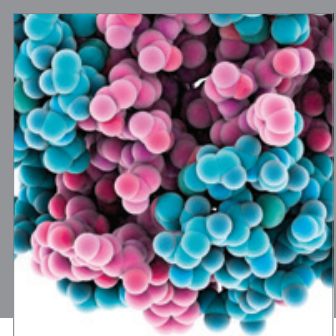

Journal of
Diabetes Research

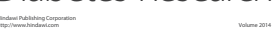

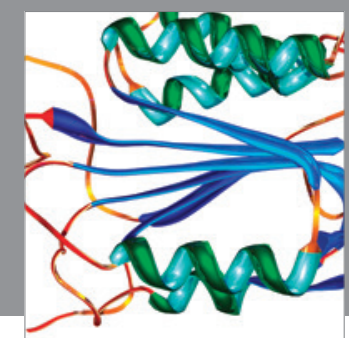

Disease Markers
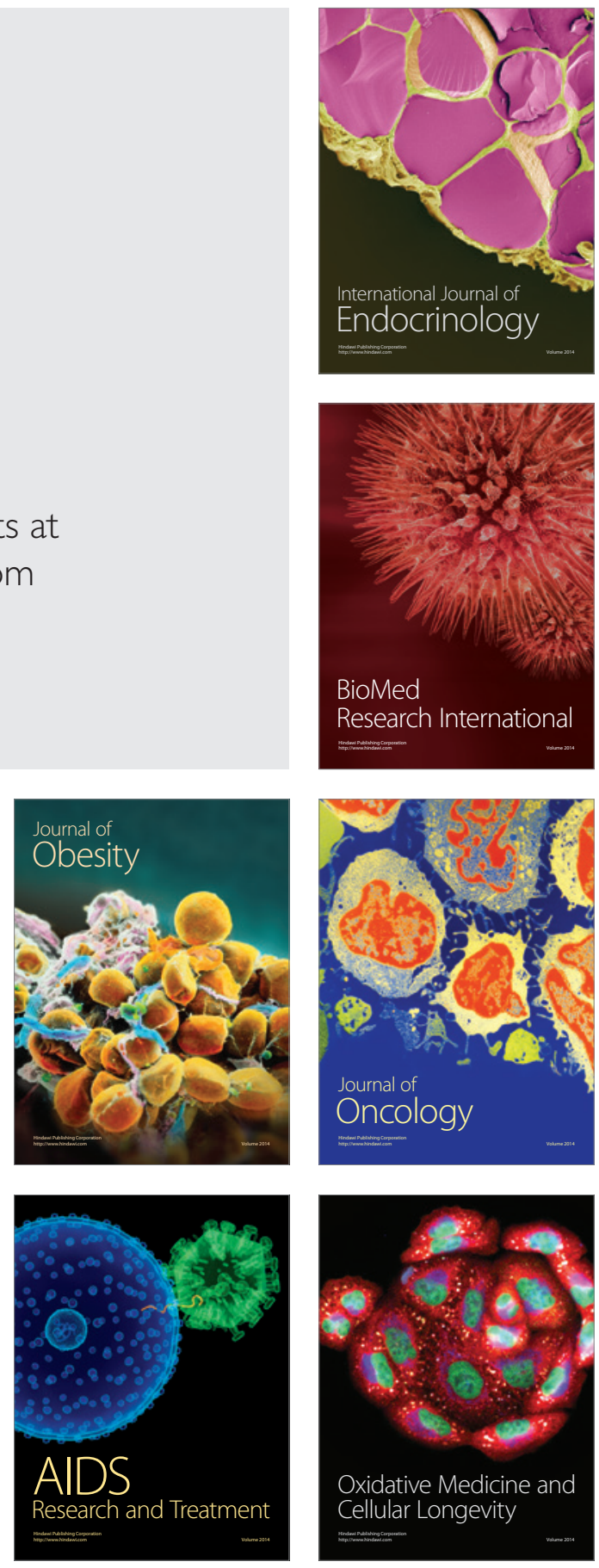